\title{
APPLICATION OF A NEW COMPUTATIONAL METHOD TO CALCULATE THE MIXTURE COMPOSITION OF MAGNESIUM OXYCHLORIDE CEMENT
}

\author{
WEIXIN ZHENG $*, * *, * * *,{ }^{*}$ XUEYING XIAO*,**, JING WEN*,**, JINGMEI DONG*,**, YING LI*,**, \\ CHENGGONG CHANG*,**, QING HUANG $*, * *, * * *$, YANGYANG MAN ${ }^{*}, * *, * * *$, YUAN ZHOU $*, * *$ \\ *Key Laboratory of Comprehensive and Highly Efficient Utilization of Salt Lake Resources, Qinghai Institute of Salt Lakes, \\ Chinese Academy of Sciences, No.18, Xinning Road, Xining 810008, PR China \\ **Key Laboratory of Salt Lake Resources Chemistry of Qinghai Province, Qinghai Institute of Salt Lakes, \\ Chinese Academy of Sciences, No.18, Xinning Road, Xining 810008, PR China \\ ***University of Chinese Academy of Sciences, \\ No. 19, Yuquan Road, Beijing 100049, PR China \\ "E-mail: gmp8828@sina.com
}

Submitted November 14, 2018; accepted January 7, 2019

\begin{abstract}
Keywords: Mixture design, Composite materials, Microstructure
Magnesium oxychloride cement (MOC) is a kind of pneumatic and hard cementitious material made by mixing magnesium oxide, magnesium chloride and water in certain proportions. The mixture proportion of the magnesium oxychloride cement materials is relatively complicated in a practical application. In this paper, through a physical property experiment on industrial bischofite in tap water, the constant difference of the mass percentage concentration and the Baumé degree of $\mathrm{MgCl}_{2}$ were studied. The traditional design method was modified and a new simplified method of magnesium oxychloride cement material mixture was established. In order to verify the applicability of the new method, two kinds of MOC foam concretes have been prepared according to the proportions of the raw materials calculated by the traditional and new method, respectively. The performances of the two were analysed carefully, and the results exhibit that the two kinds of samples have similar mechanical properties and microstructures. It is indicated that the simplified process can be applied to the magnesium oxychloride cement material mixture and has important practical significance for the industrial production of magnesium oxychloride cement materials.
\end{abstract}

\section{INTRODUCTION}

Magnesium oxychloride cement (MOC) is formed by the addition of a magnesium chloride solution $\left(\mathrm{MgCl}_{2}-\mathrm{H}_{2} \mathrm{O}\right)$ to a fine powder of magnesite or dolomite with a major component being caustic $\mathrm{MgO}_{\mathrm{a}}[1,2]$. Compared to Portland cement, it possesses many advantages, including a lighter weight, a higher strength, no need for humidity curing, antifreeze and resistance to halogen $[3,4]$. This makes it a very popular construction and building material [5]. Recently, the development of MOC has undergone rapid changes. For example, many new industrial applications have been discovered, such as door frames, fireproof materials, floor tiles, foamed material, thermal insulation materials, road material in high saline and high cold area, etc. [6-11]. Generally, the hydration products of mixing magnesium oxide, magnesium chloride and water are phase $3\left(3 \mathrm{Mg}(\mathrm{OH})_{2} \cdot \mathrm{MgCl}_{2} \cdot 8 \mathrm{H}_{2} \mathrm{O}\right)$ and phase $5\left(5 \mathrm{Mg}(\mathrm{OH})_{2} \cdot \mathrm{MgCl}_{2} \cdot 8 \mathrm{H}_{2} \mathrm{O}\right)[1,3-6]$, and the composition of the hydration products depends on the molar ratios of $\mathrm{MgO}_{\mathrm{a}} / \mathrm{MgCl}_{2}$ and $\mathrm{H}_{2} \mathrm{O} / \mathrm{MgCl}_{2}$ [12, 27]. The research results demonstrate that the performance of MOC approaches the optimal when the value of $n$ $\left(\mathrm{MgO} / \mathrm{MgCl}_{2}\right)$ reaches 4-6 [13]. When the molar ratio of $\mathrm{MgO} / \mathrm{MgCl}_{2}$ is less than 6 , the $\mathrm{MgO}$ content in the hydration products increases with an increase in the molar ratio of $\mathrm{MgO} / \mathrm{MgCl}_{2}$, which makes the raw solution more alkaline and successively ensures the stability of the phases of MOC [14]. However, through long-term performance monitoring and research, it was found that a reasonable molar ratio of $\mathrm{MgO} / \mathrm{MgCl}_{2}$ ranges from 5 to 10 , and when it was close to 7 , the mechanical performance of MOC was the best $[15,16]$.

Consequently, most producers fix the molar ratio of $\mathrm{MgO} / \mathrm{MgCl}_{2}$ to 7 in the current MOC applications. If the molar ratio of $\mathrm{MgO} / \mathrm{MgCl}_{2}$ is fixed to a constant, the relationship between the brine and $\mathrm{MgO}$ dosage can be deduced, as shown in Equation 1. Therefore, the proportion relationship between $\mathrm{MgO}, \mathrm{MgCl}_{2}$ and $\mathrm{H}_{2} \mathrm{O}$ was calculated in industrial applications to stabilise the properties of the MOC products according to the mix proportions derived from Equations 1, 2 and 3.

$$
\begin{gathered}
\frac{m_{\mathrm{Br}}}{m_{\mathrm{MO}}}=\frac{95 a}{40 n C} \rightarrow \frac{V}{m_{\mathrm{MO}}}=2.375 \frac{a}{n C p} \\
C=\frac{m_{\mathrm{MC}}}{m_{\mathrm{MC}}+m_{\mathrm{HO}}} \rightarrow \frac{m_{\mathrm{HO}}}{m_{\mathrm{MC}}}=\frac{1}{C}-1
\end{gathered}
$$




$$
B a=\left[144.3-\left(\frac{144.3}{\gamma}\right)\right]=\left[144.3-\left(\frac{144.3}{\rho / 1000}\right)\right]
$$

where, $m_{\mathrm{Br}}, m_{\mathrm{MO}}, m_{\mathrm{MC}}$ and $m_{\mathrm{HO}}$ represent the weight of the brine, the light-burnt magnesia, the bischofite and $\mathrm{H}_{2} \mathrm{O}$, respectively; $a$ is the activity content of the light-burnt magnesia $\left(\mathrm{MgO}_{\mathrm{a}}\right)$; $n$ is the molar ratio of $\mathrm{MgO}_{\mathrm{a}} / \mathrm{MgCl}_{2}$; $C$ is the mass concentration of $\mathrm{MgCl}_{2}$ in the brine; $V, \rho$ and $\gamma$ represent the volume, density and specific gravity of the brine, respectively; $B a$ is the Baumé degree.

In the previous research, since the same magnesium oxide was used, the observed variations in the standard consistencies and setting times of the MOC are related to the concentration of the brine [17]. The mass concentration of the $\mathrm{MgCl}_{2}$ solution determines the phase composition and the stability of MOC $[14,15,18]$, and can be measured with a glass hydrometer with a unitscale of 0.01 . The Baumé degree was first introduced by the French chemist, Antoine Baumé, and was one way to represent the concentration of the saline solution. A high Baumé degree was adopted as the standard in this paper, and the salt solution with a mass concentration of $15 \%$ is assigned to 15 , and the pure water to zero and the entire amount was divided into 15 graduated scales. The scales were extended to 15 and above to measure the high concentration, the unit is 1 graduated scale. Because the Baumé degree is larger and easy to read, in order to accurately control the proportion of MOC raw materials, the mass concentration of the solution is usually calculated by the Baumé degree in industrial production. When the Baumé degree is measured, the density of solution was deduced by the Baumé degree-solution density formula (Equation 3), the mass concentration of the solution is discovered from the comparison table of the chemistry manual. Finally, the dosage of the raw materials during the production was calculated by the mass concentration. For example, in order to ascertain the dosage of the brine, firstly, the Baumé degree $(B a)$ of the solution was measured. Then $\rho$ was calculated by Equation 3 and the value of $C$ was determined according to Handbook of Chemistry [19]. As mentioned above, the value of $n$ was fixed, the value of $a$ was measured through the hydration experiment of the magnesium oxide [20], when the demanded quantity of $\mathrm{MgO}$ was known. Finally, the dosage of the brine was calculated by Equation 1. In practical engineering applications, however, technicians would like to get the amount of brine directly and effortlessly. This method may become more complicated for acquiring the amount of each ingredient in the initial MOC batching.

Additionally, the current raw bischofite for the MOC product is generally obtained from the by-product of a potash fertiliser or sea salt, where the impurity mass content can be $2 \%$ or more, see Table 1 . Because the $\mathrm{MgCl}_{2}$ mass concentration standard of the chemistry handbook was defined by a high purity raw material, some errors may be involved in the practical industrial application when we use an impure raw material and consulting the standard. This may finally lead to bischofite usage variance in practice. There are very few studies directly focusing on the Baumé degree for calculating the mixture proportions. The present paper seeks to fill this fundamental knowledge gap, revise and simplify the calculation method of the MOC raw material mix ratio, and improves the exactness in an impure bischofie industrial application. The practicability of this method is experimentally proved.

\section{EXPERIMENTAL}

\section{Materials}

The raw materials for preparing MOC include light-burnt magnesia, bischofite, fly ash and a foam. The light-burnt magnesia (Haicheng Magnesium Cement Mining, China) with a content of active magnesium oxide of $63.73 \%$ by weight, which was tested at $105^{\circ} \mathrm{C}$ and $101.3 \mathrm{kPa}$ by the hydration method and citric acid method [21], was used in this study. The chemical composition of the light-burnt magnesia, as determined by X-ray fluorescence (Axios PW4400), is summarised in Table 1.

The bischofite used in this paper was a by-product of the extraction of potassium in the Salt Lake (Qinghai Province, China), the content of $\mathrm{MgCl}_{2} \cdot 6 \mathrm{H}_{2} \mathrm{O}$ was 98.5 wt. \%. The chemical composition of the bischofite are given in Table 1. The Salt Lake bischofite (SLB) occupies majority of the commercial applications of MOC, so it was selected as the research object in this paper.

Table 1. The chemical composition of the light-burnt magnesia and bischofite.

\begin{tabular}{lcllr}
\hline \multicolumn{2}{c}{ Light-burnt Magnesia } & & \multicolumn{2}{c}{ Bischofite } \\
\cline { 1 - 2 } Component & Content (wt. \%) & & Component & Content (wt. \%) \\
\cline { 1 - 2 } Magnesium oxide $(\mathrm{MgO})$ & 85.24 & & Magnesium chloride $\left(\mathrm{MgCl}_{2}\right)$ & 46.43 \\
Calcium oxide $(\mathrm{CaO})$ & 1.64 & & Potassium chloride $(\mathrm{KCl})$ & 0.21 \\
Aluminium oxide $\left(\mathrm{Al}_{2} \mathrm{O}_{3}\right)$ & 0.21 & & Sodium chloride $(\mathrm{NaCl})$ & 0.36 \\
Silicon dioxide $\left(\mathrm{SiO}_{2}\right)$ & 4.70 & & Calcium chloride $\left(\mathrm{CaCl}_{2}\right)$ & 0.01 \\
Ferric oxide $\left(\mathrm{Fe}_{2} \mathrm{O}_{3}\right)$ & 0.29 & & Magnesium sulfate $\left(\mathrm{MgSO}_{4}\right)$ & 0.02 \\
Loss on ignition & 7.92 & & Water insolubles & 0.07 \\
& & & Crystal water & 52.90 \\
\hline
\end{tabular}


Brine experiments

The brine was prepared by dissolving bischofite in tap water. In order to accurately reflect the correspondence between the mass percentage concentration, density and Baumé degree of the brine, the test was carried out three times (T-1, T-2 and T-3) while the ambient temperature $\left(20{ }^{\circ} \mathrm{C}\right)$ was kept unchanged. In every experiment, a measured weight of solid bischofite was first placed in a measuring cylinder. Tap water was then slowly added into the measuring cylinder until the threshold point when bischofite was just completely dissolved. It can be deduced from this point that the brine reached its saturation point. After that, $100 \mathrm{~g}$ of water was added to the saturated solution and stirred for 1 minute with the aid of a glass rod forming a mixture solution. After that, the mixture solution was tested for the Baumé degree $\left(B a_{\mathrm{s}}\right)$ and density $\left(\rho_{\mathrm{S}}\right)$. Such a process was repeated ten times, which is summarised in Table 2.

\section{MOC foam concrete experiment and analyses}

The dosages of the recipes are presented in Table 4 . All the kinds of powders were mixed thoroughly, and then the brine was added to the blended mixture. The foam, made by the foaming mechanism (the foaming machine and foaming agent was produced by Ketai, Ltd. Shandong Province, China), was added. It was then mixed for a few minutes to produce the MOC foam concrete. The well-mixed MOC foam concrete paste was poured into the prefabricated mould (a mould of size of $3 \times 0.6$ $\times 0.09 \mathrm{~m})$.

The raw materials of the MOC with a certain proportion were mixed completely into the pastes, introducing the foam which was made by the foaming mechanism, entering the mould (the size of $3 \times 0.6 \times$ $0.09 \mathrm{~m}$ ) for solidification under the conditions of room temperature $\left(>15^{\circ} \mathrm{C}\right)$. The samples should be cultivated in the air after being drawn off the mould. The samples were cut into standard test blocks $(1=100 \mathrm{~mm})$, and they were used to conduct the compressive strength analysis of the test by the material testing system (SANYU, SYE$3000 \mathrm{D}$ ) with the maximum load of $3000 \mathrm{KN}$ at a loading rate of $0.05 \pm 0.1 \mathrm{MPa} / \mathrm{s}$. The compositions of the MOC foam concrete were measured by XRD (PANalytical X'pert Pro; $\mathrm{Cu} \mathrm{K \alpha}$ radiation at $40 \mathrm{kV} / 30 \mathrm{~mA}$; scan rate of $\left.0.02^{\circ} \cdot \mathrm{s}^{-1}\right)$. The particles prepared for XRD were less than $75 \mu \mathrm{m}$. The quantitative compositions of the specimens were carried out by the Rietveld method with Topas 4.2 software according to the XRD pattern [22]. The micro-morphology on the fractured surface of the MOC foam concrete pastes were characterised by SEM (JSM-5610LV) with a gold coating.

\section{RESULTS AND DISCUSSION}

The derived equations

In Table 2, $C_{\mathrm{S}}$ is the mass concentration of the SLB in tap water. Furthermore, both $C_{\mathrm{S}}$ and $B a_{\mathrm{S}}$ have a linear growth trend and the average difference is 0.9. Therefore, the relationship between the Baumé degree and the mass concentration can be determined as follows:

$$
\text { Avg. }\left(B a_{\mathrm{S}}-C_{\mathrm{S}}\right)=0.9
$$

The standard data was derived from the chemical manual (Table 3) [19]. The average value of $\left(B a_{i}-C_{i}\right)$ was 0.7 , the difference value, compared with the value, was calculated by Equation 4, the difference value was 0.2 This situation was attributed to the ions and impurities (Table 1) of the SLB, which is unavoidable. However, in practical engineering applications, especially for MOC applications, the impact is quite small.

According to Equation 4 and $B a$, the modified Baumé degree $\left(\mathrm{Ba}_{i}{ }_{i}=\mathrm{C}_{i}+0.9\right)$ was obtained. As shown in Figure $1, B a^{\prime}$ is very close to $B a$. The Baumé degree usually involved in the practical application of MOC is between 20 and $30{ }^{\circ} \mathrm{Be} '[11,15,23]$. Although there are large fluctuations below $C=6 \%$ (for example, $\left|\Delta_{4}\right|=1.6$ ), the two curves above $6 \%$ have a very high coincidence

Table 2. The test data of the brine.

\begin{tabular}{|c|c|c|c|c|c|c|c|c|c|c|c|}
\hline \multicolumn{3}{|c|}{$m_{\mathrm{HO}} / m_{\mathrm{Bi}} *$} & \multicolumn{3}{|c|}{$B a_{\mathrm{s}}\left({ }^{\circ} \mathrm{Be}^{\prime}\right)$} & \multicolumn{3}{|c|}{$\rho_{\mathrm{S}}\left(\mathrm{kg} \cdot \mathrm{m}^{-3}\right)$} & \multicolumn{3}{|c|}{$C_{\mathrm{S}} *(\%)$} \\
\hline $\mathrm{T}-1$ & T-2 & T-3 & T-1 & $\mathrm{T}-2$ & T-3 & T-1 & T-2 & T-3 & T-1 & T-2 & T-3 \\
\hline 0.554 & 0.526 & 0.523 & 31.0 & 31.5 & 31.3 & 1276 & 1282 & 1282 & 29.7 & 30.2 & 30.3 \\
\hline 0.654 & 0.632 & 0.623 & 28.0 & 30.0 & 29.5 & 1256 & 1260 & 1264 & 27.9 & 28.3 & 28.4 \\
\hline 0.754 & 0.737 & 0.723 & 26.5 & 27.5 & 27.5 & 1239 & 1243 & 1243 & 26.3 & 26.5 & 26.8 \\
\hline 0.854 & 0.842 & 0.823 & 25.5 & 26.0 & 27.0 & 1224 & 1227 & 1239 & 24.9 & 25.0 & 25.3 \\
\hline 0.954 & 0.947 & 0.922 & 24.2 & 23.5 & 25.0 & 1212 & 1212 & 1215 & 23.6 & 23.7 & 24.0 \\
\hline 1.054 & 1.053 & 1.022 & 23.0 & 23.0 & 24.0 & 1201 & 1201 & 1204 & 22.4 & 22.5 & 22.8 \\
\hline 1.154 & 1.158 & 1.122 & 22.0 & 22.0 & 23.0 & 1191 & 1192 & 1194 & 21.4 & 21.4 & 21.7 \\
\hline 1.254 & 1.263 & 1.221 & 21.0 & 21.5 & 22.0 & 1182 & 1181 & 1183 & 20.5 & 20.4 & 20.8 \\
\hline 1.354 & 1.368 & 1.321 & 20.0 & 20.5 & 21.0 & 1167 & 1173 & 1176 & 19.6 & 19.5 & 19.9 \\
\hline 1.454 & 1.474 & 1.421 & 19.5 & 20.0 & 20.0 & 1165 & 1166 & 1168 & 18.8 & 18.6 & 19.0 \\
\hline 1.554 & 1.579 & 1.520 & 19.0 & 19.0 & 19.5 & 1158 & 1159 & 1161 & 18.0 & 17.9 & 18.3 \\
\hline
\end{tabular}

$m_{\mathrm{Bi}}{ }^{*}$ : the quality of the bischofite; $C_{\mathrm{S}}{ }^{*}=\left(m_{\mathrm{MC}} \times 46.10 \%\right) /\left[m_{\mathrm{HO}}+m_{\mathrm{MC}} \times(100-46.10) \%\right] \times 100 \%$ 
degree (for example, $\left|\Delta_{6 \sim 30}\right| \leq 0.3$ ). It can be concluded that when the SLB is dissolved in tap water, the modified Equation 4 can accurately reflect the relationship between $\mathrm{C}$ and $\mathrm{Ba}$ of $\mathrm{MgCl}_{2}$. Based on the above experiments and derivations, the derived Equations 1 and 2 can be finally determined as the modified Equations 5 and 6 which are more suitable for the raw material ratio calculation of MOC.

$$
\begin{gathered}
\frac{m_{\mathrm{Br}}}{m_{\mathrm{MC}}}=2.375 \frac{a}{n(B a-0.9)} \\
\frac{v}{m_{\mathrm{MO}}}=\mathrm{A} \frac{a(144.3-B a)}{n(B a-0.9)} \quad \mathrm{A}=1.646 \times 10^{-5}
\end{gathered}
$$

From the modified Equations 5 and 6, we can see that the quantity of the brine or $\mathrm{MgCl}_{2}$ and $\mathrm{H}_{2} \mathrm{O}$ can be calculated directly by the Baumé degree $(B a)$, not like the one mentioned in the introduction section: Firstly, the density $(\rho)$ was calculated by Equation 3 after the measurement of $B a$, and then the value of the mass concentration $(C)$ was determined according to the Handbook of Chemistry, finally, the quantities of the raw materials were calculated by Equations 1 and 2 . Because this new method does not need to calculate

Table 3. The standard data of the brine.

\begin{tabular}{ccccc}
\hline$C(\%)$ & $\rho\left(\mathrm{kg} \mathrm{m}^{-3}\right)$ & $B a\left({ }^{\circ} \mathrm{Be}\right)$ & $B a^{\prime}\left({ }^{\circ} \mathrm{Be}^{\prime}\right)$ & $\mathrm{Ba}_{i}-\mathrm{C}_{i}$ \\
\hline 2 & 1014.6 & 2.1 & 2.9 & 0.1 \\
4 & 1031.1 & 3.3 & 4.9 & -0.7 \\
6 & 1047.8 & 6.6 & 6.9 & 0.6 \\
8 & 1064.6 & 8.8 & 8.9 & 0.8 \\
10 & 1081.6 & 10.9 & 10.9 & 0.9 \\
12 & 1098.9 & 13.0 & 12.9 & 1.0 \\
14 & 1116.4 & 15.0 & 14.9 & 1.0 \\
16 & 1132.4 & 16.8 & 16.9 & 0.8 \\
18 & 1152.3 & 19.0 & 18.9 & 1.0 \\
20 & 1170.6 & 21.1 & 20.9 & 1.1 \\
25 & 1218.4 & 25.8 & 25.9 & 0.8 \\
30 & 1268.8 & 30.6 & 30.9 & 0.6 \\
\hline
\end{tabular}

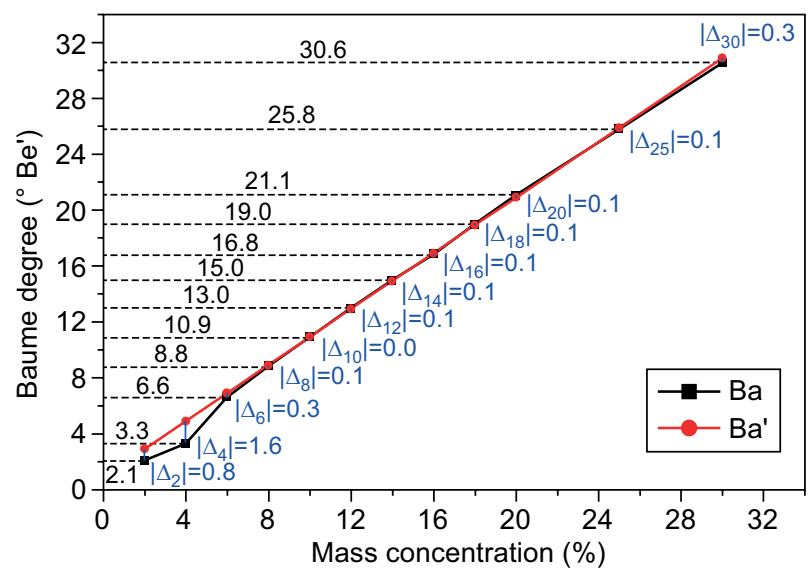

Figure 1. The trend charts of the modified and standard Baumé degree, $\left|\Delta_{i}\right|=\left|B a^{\prime}{ }_{i}-B a_{i}\right|$. the density of the solution and search the chemistry handbooks, the whole process is simplified for MOC engineers, and it is favourable for MOC industrial manufacture. Additionally, as described in the Introduction, the bischofite used in MOC was a by-product of the extraction of potassium in the Salt Lake, the impurity mass content of it can be $2 \%$ or more. Because the $\mathrm{MgCl}_{2}$ mass concentration standard of the chemistry handbook was defined by high purity raw material, there may involve some errors in the practical industrial application when we use an impure raw material and consulting the standard. As the modified Equations omitted the calculation of the density and the mass concentration does not have reference standard parameters, it thus reduces the calculation error in many applications of nonpure Magnesium chloride $\left(\mathrm{MgCl}_{2}\right)$ and helps to control the SLB dosage accurately in the practical application.

\section{The practical application of the derived equations}

To verify the accuracy of the modified Equations 5 and 6 in a practical application, the comparisons of both methods (derived and modified) and the final product performance was made. The derived equation experiment was code-labelled as E-1 and the modified equations experiment was denoted as E-2. As shown in Table 4, the dosage of the raw materials of E-1 and $\mathrm{E}-2$ were identical. The molar ratio of the active $\mathrm{MgO}$ to $\mathrm{MgCl}_{2}\left(\mathrm{MgO}_{\mathrm{a}} / \mathrm{MgCl}_{2}\right)$ was kept constant at $n=7$ and the concentration of the brine was $B a=26^{\circ} \mathrm{Bé}$ in this experiment. The content of the fly ash additives was $m_{\mathrm{FA}}=50 \mathrm{~kg}$ and the foam output was $V_{\mathrm{FO}}=0.88 \mathrm{~m}^{3}$. The largest difference between the two methods is that the measurement and calculation $\rho=1219.8 \mathrm{~kg} \cdot \mathrm{m}^{-3}$ and $C=25 \%$ in E-2 can be neglected. However, in E-1 (as described in the introduction above), the information of $\rho$ and $C$ must be obtained through extrapolation. The calculation results show that the quality of the bischofite or the volume of the brine are very close, $m_{\mathrm{Br}}=248.4 \mathrm{~kg}$ and $V_{\mathrm{Br}}=203.61$ in E-1, $m_{\mathrm{Br}}=247.4 \mathrm{~kg}$ and $V_{\mathrm{Br}}=202.81$ in $\mathrm{E}-2$.

Table 4. The calculation of the mixture proportions.

\begin{tabular}{lcc}
\hline Calculate target & $\mathrm{E}-1$ & $\mathrm{E}-2$ \\
\hline$a(\mathrm{wt} . \%)$ & 61 & 61 \\
$n\left(\mathrm{Be}^{\prime}\right)$ & 7 & 7 \\
$B a$ & 26 & 26 \\
$m_{\mathrm{MO}}(\mathrm{kg})$ & 300 & 300 \\
$m_{\mathrm{FA}}(\mathrm{kg})$ & 50 & 50 \\
$V_{\mathrm{FO}}\left(\mathrm{m}^{3}\right)$ & 0.88 & 0.88 \\
$\rho\left(\mathrm{kg} \mathrm{m}^{-3}\right)$ & 1219.8 & - \\
$C(\%)$ & 25 & - \\
$m_{\mathrm{Br}}(\mathrm{kg})$ & 248.4 & 247.4 \\
$V_{\mathrm{Br}}(\mathrm{l})$ & 203.6 & 202.8 \\
\hline
\end{tabular}




\section{Contrastive analysis}

The compressive strength of the MOC foam concrete

The compressive strengths of the MOC foam concrete specimens from 7 days to 28 days curing time are shown in Figure 2. The compressive strengths of E-1 and E-2 at the early age (the first 14 days) were growing quickly and the later age tended to reach stabilisation. The mechanical property tendency of the concretes is consistent and only slightly different at 21 days. The compressive strengths of E-1 and E-2 are $5.18 \mathrm{MPa}$ and $5.31 \mathrm{MPa}$ at 21 days, respectively. The small gap $\left(\Delta_{21}=0.13 \mathrm{MPa}\right)$ was not magnified at 28 days $\left(\Delta_{28}=\right.$ $=0.07 \mathrm{MPa}$ ), Thus, the mechanical property of E-2 were relatively stable.

\section{The XRD and SEM of the MOC foam concrete}

Figure 3 shows the XRD patterns of the MOC foam concrete at 28 days. It can be seen from Figure 3 that E-2 has a similar hydration product to E-1. The mineralogical phases of both concretes were mostly made of Phase 5

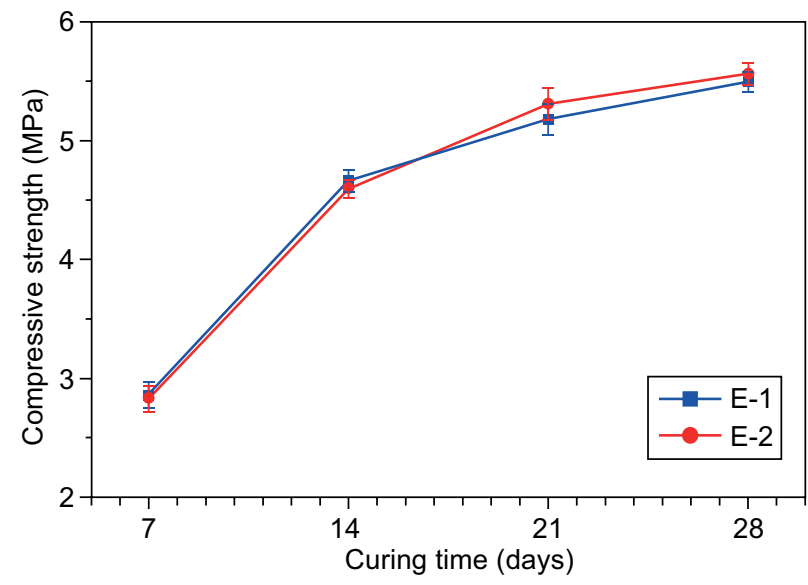

Figure 2. The compressive strength of the MOC foam concrete specimens cured in the air.

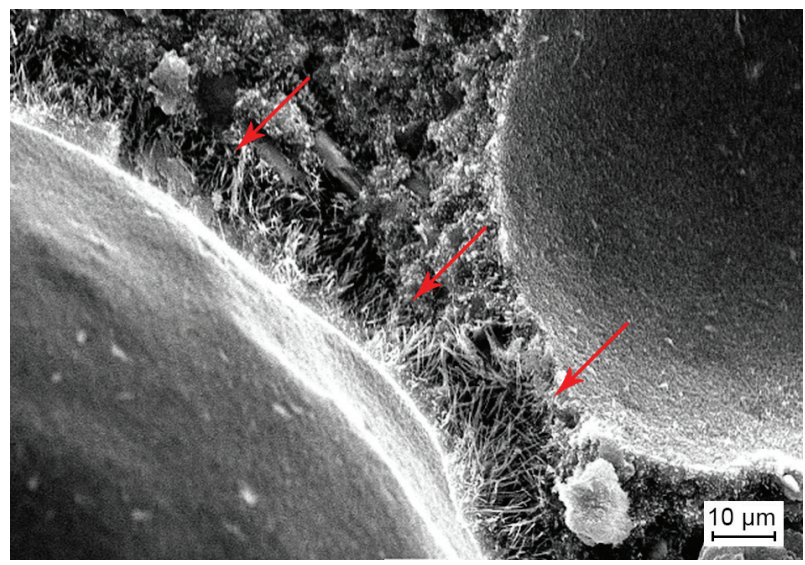

a) E-2 and a little $\mathrm{MgO}, \mathrm{MgCO}_{3}$ and $\mathrm{SiO}_{2}$. Besides for Phase 5, other mineralogical phases may have originated from the light burnt magnesia or fly ash. The studies have shown that at room temperature and atmospheric pressure, the chemical reactions in the $\mathrm{MgO}-\mathrm{MgCl}_{2}-\mathrm{H}_{2} \mathrm{O}$ system may happen per the following equations [24]:

$$
\begin{aligned}
& 5 \mathrm{MgO}+\mathrm{MgCl}_{2}+13 \mathrm{H}_{2} \mathrm{O}= \\
& =5 \mathrm{Mg}(\mathrm{OH})_{2} \cdot \mathrm{MgCl}_{2} \cdot 8 \mathrm{H}_{2} \mathrm{O} \quad \text { (Phase 5) } \\
& 3 \mathrm{MgO}+\mathrm{MgCl}_{2}+11 \mathrm{H}_{2} \mathrm{O}= \\
& =3 \mathrm{Mg}(\mathrm{OH})_{2} \cdot \mathrm{MgCl}_{2} \cdot 8 \mathrm{H}_{2} \mathrm{O} \quad \text { (Phase 3) } \\
& \mathrm{MgO}+\mathrm{H}_{2} \mathrm{O}=\mathrm{Mg}(\mathrm{OH})_{2}
\end{aligned}
$$

The above equations indicate that the hydration product of MOC depends on the ratio of the raw materials including the molar ratios of $\mathrm{MgO} / \mathrm{MgCl}_{2}$ and $\mathrm{H}_{2} \mathrm{O} / \mathrm{MgCl}_{2}$. In addition, the active $\mathrm{MgO}$ affects the hydration product of MOC [25]. Hence, the hydration products in MOC could include Phase 5, Phase $3, \mathrm{Mg}(\mathrm{OH})_{2}$, or two or three of them. It can be seen from the SEM images in Figure 4 that the microstructure of E-2 is similar

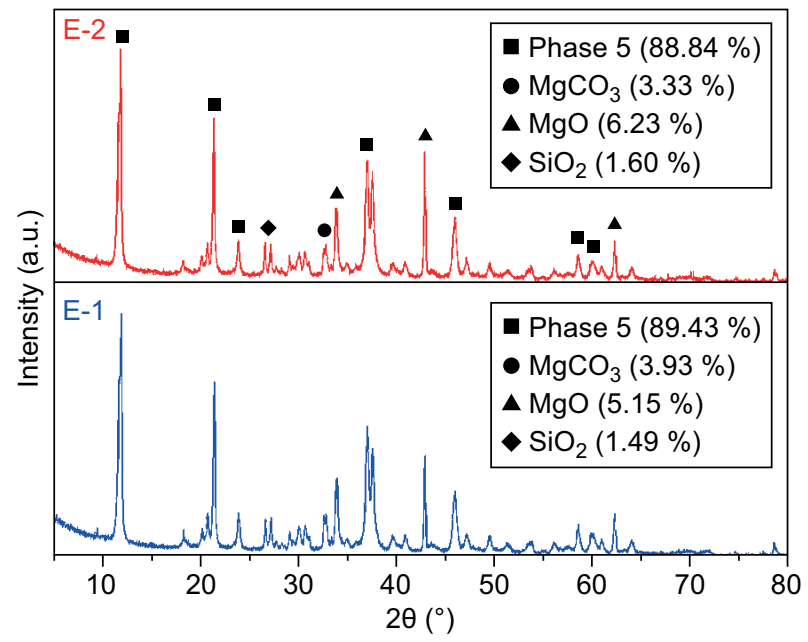

Figure 3. The XRD diffractograms and SEM images of E-1 and $\mathrm{E}-2$ at 28 days.

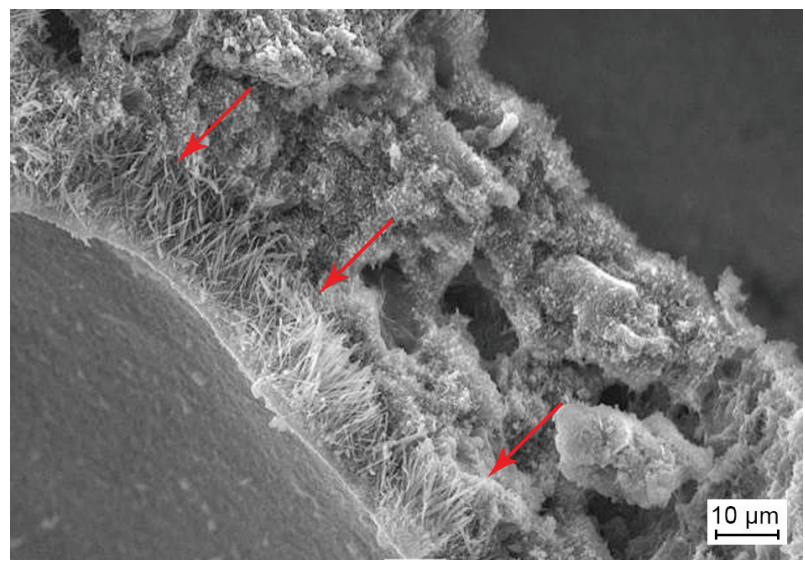

b) E-1

Figure 4. The SEM images of E-1 and E-2 at 28 days. 
to E-1. The reaction products in a needle shape are obviously seen in both E-2 and E-1. The Phase 5 crystal length and content in the pore wall structures (the area indicated by a red arrow) of the two MOC foam concrete samples are similar. The dense crystal and spidery Phase 5 needle rod-like crystals interlacing with each other lead to the MOC obtaining a high strength $[26,27]$. The samples E-1(89.43\%) and E-2(88.84 \%) have similar performance because they have similar crystal ratios and quantities. Therefore, the results of the XRD and SEM are consistent.

\section{CONCLUSION}

In this paper, through a physical property experiment on industrial bischofite in tap water and an improvement on the traditional design method, a much simpler method has been employed to design the mixture proportions of magnesium oxychloride cement (MOC) materials. A series of tests on the compressive strength, compositions and microstructures of the MOC foam concrete have been carried out. Based on the experimental results, the following conclusions can be drawn:

- In the SLB dissolved brine, the constant difference of mass percentage concentration and Baumé degree of $\mathrm{MgCl}_{2}$ was 0.9 .

- The establishment of the relationship has simplified the calculation process of the MOC material mixture proportions. Relative to the conventional methods, the modified equations obtained through the simplification have also demonstrated a stable performance when it is used in the actual production of MOC.

- The sample, made by the simplified and traditional method, have similar mechanical properties and microstructures, which indicates that the simplified process can be applied to the MOC material mixture. This approach has important practical significance for the industrial production of MOC materials.

\section{Acknowledgments}

The authors would like to acknowledge the financial support from the Major Science and Technology Projects of Qinghai Province (2014-GX-A2A), the Science and Technology Achievements Transformation Project of Qinghai Province (2018-NN-152) and the National Natural Science Foundation of China (U1507120, 51608512).

\section{REFERENCES}

1. Sorre C., Armstrong C. (1976): Reactions and equilibria in Magnesium Oxychloride Cements. Journal of the American Ceramic Society, 59(1-2), 51-54. doi:10.1111/ j.1151-2916.1976.tb09387.x
2. Mahmut A., Mehmet Y. (2017): Study of using dolomite as starting material resource to produce magnesium oxychloride cement. Journal of Advanced Concrete Technology, 15(6), 269-277. doi: 10.3151/jact.15.269

3. He P., Poon C.S., Tsang D. C.W. (2017): Effect of pulverized fuel ash and $\mathrm{CO}_{2}$ curing on the water resistance of magnesium oxychloride cement (MOC). Cement and Concrete Research, 97, 115-122. doi: 10.1016/j.cemconres. 2017.03.005

4. Li J., Li G., Yu Y. (2008): The influence of compound additive on magnesium oxychloride cement/urban refuse floor tile. Construction and Building Materials, 22, 521-525. doi: 10.1016/j.conbuildmat.2006.11.010

5. Power I., Dipple G., Francis P. (2017): Assessing the carbon sequestration potential of magnesium oxychloride cement building materials. Cement and Concrete Composites, 78, 97-107. doi: 10.1016/j.cemconcomp.2017.01.003

6. Zhou X., Li Z. (2012): Light-weight wood-magnesium oxychloride cement composite building products made by extrusion. Construction and Building Materials, 27(1), 382-389. doi: 10.1016/j.conbuildmat.2011.07.033

7. Montle, J., Mayhan, K. (1974): The role of magnesium oxychloride as a fire-resistive material. Fire Technology, 10(3), 201-210. doi: 10.1007/BF02588845

8. Ji Y. (2001): Study of the new type of light magnesium cement foamed material. Materials Letters, 50(1), 28-31. doi: 10.1016/S0167-577X(00)00407-9

9. Li G., Yu Y., Li J., Wang Y., Liu H. (2003): Experimental study on urban refuse/ magnesium oxychloride cement compound floor tile. Cement and Concrete Research, 33(10), 1663-1668. doi: 10.1016/S0008-8846(03)00136-4

10. Karimi Y., Monshi A. (2011): Effect of magnesium chloride concentrations on the properties of magnesium oxychloride cement for nano $\mathrm{SiC}$ composite purposes. Ceramics International, 37(7), 2405-2410. doi: 10.1016/j.ceramint. 2011.05.082

11. Qiao, X., Gong, W., Shi, Y., Elizabeth, M.W., Dong, J. (2016): Experimental study on magnesium oxychloride cement concrete Emerging Materials Research, 5(2), 248-255. doi: 10.1680/jemmr.16.00012

12. Li Y., Yu H., Zheng L., Wen J., Wu C., Tan Y. (2013): Compressive strength of fly ash magnesium oxychloride cement containing granite wastes. Construction and Building Materials, 38, 1-7. doi: 10.1016/j.conbuildmat.2012.06.016

13. Bilinski H., Matkovic B., Mazuranic C., Zunic T.B. (1984): The formation of magnesium oxychloride phases in systems $\mathrm{MgO}-\mathrm{MgCl}_{2}-\mathrm{H}_{2} \mathrm{O}$ and $\mathrm{NaOH}-\mathrm{MgCl}_{2}-\mathrm{H}_{2} \mathrm{O}$. Journal of the American Ceramic Society, 67(4), 266-269. doi: 10.1111/ j.1151-2916.1984.tb18844.x

14. Ba H., Guan H. (2009): Influence of $\mathrm{MgO} / \mathrm{MgCl}_{2}$ molar ratio on phase stability of magnesium oxychloride cement. Journal of Wuhan University of Technology, 24(3),476-481. doi: 10.1007/s11595-009-3476-3

15. Li Z., Chau C. (2007): Influence of molar ratios on properties of magnesium oxychloride cement. Cement and Concrete Research, 37, 866-870. doi: 10.1016/j.cemconres. 2007.03.015

16. Wang F., Yang L., Guan L., Hu S. (2015): Microstructure and properties of cement foams prepared by magnesium oxychloride cement. Journal of Wuhan University of Technology, 30(2), 331-337. doi: 10.1007/s11595-015-1149-y

17. Misra A.K., Mathur R. (2007): Magnesium oxychloride cement concrete. Bulletin of Materials Science, 30(3), 239-246. doi: 10.1007/s12034-007-0043-4 
18. Zhou Z., Chen H., Li Z., Li H. (2015): Simulation of the properties of $\mathrm{MgO}-\mathrm{MgfCl}_{2}-\mathrm{H}_{2} \mathrm{O}$ system by thermodynamic method. Cement and Concrete Research, 68, 105-111. doi: 10.1016/j.cemconres.2014.11.006

19. Liu G, Xiang M., Liu J. (2002): Chloride and chlorate, in: Liu., G, Xiang, M., Liu, J.: Chemical and chemical physical data manual. Chemical Industry Press, Beijing. pp. 465-466.

20. Dong J., Yu H.F., Zhang L.M. (2010): Study on experimental conditions of hydration methods of determining active magnesium oxide content, Journal of Salt Lake Research, $18,38-41$.

21. Li W., Shang H. (1987): Method for determination of activity of light-burned magnesia powder, Bulletin of the Chinese Ceramic Society, 6, 49-55.

22. Bruker (2006). Topas version 4.2. Bruker AXS. Karlsruhe, Germany.

23. Liu Z., Wang S., Huang J., Wei Z., Guan B., Fang J. (2015): Experimental investigation on the properties and microstructure of magnesium oxychloride cement prepared with caustic magnesite and dolomite. Construction and Building Materials, 85,247-255. doi: 10.1016/j.conbuildmat. 2015.01.056

24. Li Y., Li Z., Pei H., Yu H. (2016): The influence of $\mathrm{FeSO}_{4}$ and $\mathrm{KH}_{2} \mathrm{PO}_{4}$ on the performance of magnesium oxychloride cement. Construction and Building Materials, 102, 233-238. doi: 10.1016/j.conbuildmat.2015.10.186

25. Deng D. (2003): The mechanism for soluble phosphates to improve the water resistance of magnesium oxychloride cement. Cement and Concrete Research, 33(9), 1311-1317. doi: 10.1016/S0008-8846(03)00043-7

26. Deng D., Zhang C. (1999): The formation mechanism of the hydrate phases in magnesium oxychloride cement. Cement and Concrete Research, 29(9), 1365-1371. doi: 10.1016/ S0008-8846(98)00247-6

27. Abdel-Gawwad H.A., Khalil Kh.A. (2018): Preparation and characterization of one-part magnesium oxychloride cement. Construction and Building Materials, 189, 745-750. doi: 10.1016/j.conbuildmat.2018.09.051 